reactions and form stable chenical compounds. Finally, there is a description of the applications of the rare gases. Apart from their better known uses in lasers or in radioactive dating, one of the most novel and interesting uses of these gases is in medicine, in which they can apparently be used under pressure to induce total anaesthesia in man. Experiments on this are being used to establish a theory of anaesthesia. Other applications in biology are also described.

A minor criticism of the book is that some of the theory described in it is too sophisticated for first year undergraduates and sixth-formers for whom the book is intended. Further, some of the statements made are misleading. For example, at the bottom of page 35 it is implied that diatomic gas molecules do not rotate. On page 30 it is stated that ${ }^{4} \mathrm{He}$ does not have a triple point, whereas the phase diagram of ${ }^{4} \mathrm{He}$ shown on the same page clearly shows two triple points. These are minor blemishes, however, and the book makes a fine introduction to the rare gases for scientists at any level.

I. J. ZUCKER

\section{History of Science}

The Science of Matter : a Historical Survey. Edited by M. P. Crosland. Pp. 440. (Penguin: Harmondsworth, 1971.) 70p.

Steps in the Scientific Tradition: Readings in the History of Science. Edited by R.S. Westfall and V. E. Thoren. Pp. xii +544. (Wiley: New York and London, October 1971.) $£ 3.50$ cloth; $£ 1.75$ paper.

THE title of neither of these books makes its content clear. Crosland's title is the better chosen. There are 163 short extracts from important papers or books reporting original discoveries and theories, or from important critical estimates of the state of some branch of science bearing on the central theme of the constitution of matter. They are divided into some thirty groups beginning with "Theories of Matter in Ancient Greece" and ending with "Symmetry and Anti-Matter". Each group is prefaced by a short informative introduction. The total effect is one of a stimulating record of the evolution of an important aspect of man's attitude to his material circumstances.

Dr Crosland observes no boundaries of disciplines. Naturally in antiquity he has to start with the matter speculations of the Greeks, which fit into no conventional category of chemistry or physics. He includes in matter theory enough biology and astronomy to show that as a historian he himself is entirely in sympathy with the modern approach to experimental materials science in its disdain of the nineteenth century classification of study. So, with a comprehensiveness which Aristotle would have applauded, Dr Crosland ranges over the works of Newton, Proust, Lamarck, Dalton, Joule, Robert Brown, Huygens, Claude Bernard, Schwann, Kirchhoff, Einstein, Crick, ending with Dirac and Yang. Physical matter, organic matter, anti-matter: to the historian with an eye to see, it is all one story.

The extracts are necessarily short but Dr Crosland has a flair for picking out what is both important and intelligible. The material is well documented and there is a good guide to further reading. The result of what seems to have been conceived as merely an auxiliary text turns out to be a book which, in the hands of the right teacher, could be an excellent textbook for a general course in the history of science.

Paradoxically, the Westfall and Thoren book, which was planned as a textbook for a class course, does not seem nearly so likely to guide either a teacher or his class. There are twentytwo long passages from Aristotle, Ptolemy, Lucretius, Roger Bacon, Buridan, Galileo, Harvey, Descartes, Newton, Franklin, Lavoisier, Playfair, Young, Carnot, Schwann, Darwin, J. J. Thomson, T. H. Morgan, and Langmuir. Each passage is prefaced by a reflective note on its significance and on the historical lessons which may be learned from it. No doubt it may be an excellent thing for any student, who may have heard references to the celebrated thirty-first query in Newton's Opticks and even be familiar with odd quoted sentences from it, to read the whole of that marvellous chapter in the theory of matter. If he relies, however, on the editor's brief introductory note to explain why it is so marvellous, he will be left doubting, because each note only sketches lightly the intellectual situation in respect of one problem or contemporary question. A good teacher will undoubtedly explain the antecedents, the composition, the reception and ultimate influence of each passage, and the editors say that they do in fact leave the use of the book to the teacher. Why then just pick out these far from comprehensive passages and expect some unknown teacher to make a course out of them unaided?

Teachers of the history of science need help just as much as any other teachers, and this selection would have made far more sense if we had at least been told what end result its editors had got out of using it themselves, and how they had linked passage with passage. These are, in any case, too few to provide any broad sweeping view of the "scientific tradition".

The contrast between the two books tells us something important. The teach- ing of the history of science. if it is to carry any weight inside or outside the curriculum, needs the same vision of the whole as the effective teaching of science itself. The reputation of the Indiana school is high enough for us to be certain that Westfall and Thoren have such a gift, but their book does not transmit it to teachers outside. Crosland's more modest effort achieves more, shows him to possess the wider view of science as a whole, and to be able to lend his vision to others. Experienced teachers may find the Westfall-Thoren book useful. They might well find the Crosland book almost inspiring.

\section{Frank Greenaway}

\section{Computing Chemistry}

Computer Handling of Chemical Structures. By Micheal Lynch, Judith M. Harrison, William G. Town and Janet Ash. Pp. xii +148 . (Macdonald: London; Elsevier: New York, 1971.) $£ 2$.

THIS book represents a first in bringing together a brief but comprehensive overview of methods of handling chemical structure information. The first six chapters give an accurate and concise description of the various methods in use today. The descriptions are detailed enough to give the reader an indication of the philosophy and details of how each method works. The bibliography at the end of each of these six chapters provides access to those papers which represent the major work in each of the areas. The same excellent balance between detail and brevity is maintained in chapters eight and nine in which the implementation of these methods in both the publishing and industrial environments is described. Here the reader can better discern the value and limitations of each system. Unfortunately very little work has been done in identifying the system requirements met by each of the various methods, and this weakness is reflected in the general nature of chapter seven on system requirements. As the reviewer reached this chapter he had hoped to find the same incisive analysis which had been demonstrated in the earlier chapters. The last chapter outlines several areas where chemical structure information methods can have their greatest impact. The authors failed to mention in this chapter the obvious need to relate structural characteristics to chemical and biological properties.

This well written small volume should be required reading for anyone using the chemical literature, especially graduate students. C. M. BowmaN 